\title{
Dynamics and Feeding Activity of High-Density Aggregations of Oreaster reticulatus (Echinodermata: Asteroidea) in a Sand Patch Habitat
}

\author{
R. E. Scheibling* \\ Marine Sciences Centre, McGill University, Montreal, Quebec, Canada
}

\begin{abstract}
Aggregations of Oreaster reticulatus (L.) in a large sand patch amid an offshore seagrass bed (Syringodium

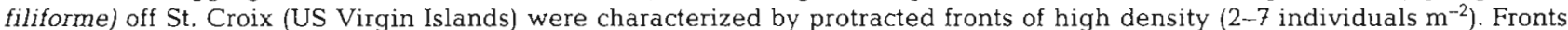
migrated across the sand patch at approximately $7 \mathrm{~m} \mathrm{~d}^{-1}$ and were refracted and deflected at the grassbed border. Intensive microphagous feeding effected a 2-fold turnover of surface sediments in the area covered by a front during $24 \mathrm{~h}$, resulting in a marked decrease in chlorophyll concentration. Conspicuously mounded feeding sites were uniformly dispersed in the wake of the fronts. Overlap among feeding sites was high indicating intraspecific competition for food.
\end{abstract}

\section{INTRODUCTION}

Echinoderms may form extremely dense feeding aggregations (review in Reese, 1966) that have a dramatic impact on the biotic environment. Migrating aggregations of the asteroid Acanthaster planci and echinoids of the genus Stronglylocentrotus have decimated extensive areas of coral reefs (review in Endean, 1973) and kelp beds (Leighton et al., 1966; Breen and Mann, 1976; Mattison et al., 1977) respectively, leaving barren areas of reduced species richness and abundance.

Oreaster reticulatus is a microphagous grazer of sand and seagrass substrata in the Caribbean (Scheibling, 1979, 1980a, b). Population density generally ranges from 2-9 individuals $100 \mathrm{~m}^{-2}$ but reached 14 individuals $100 \mathrm{~m}^{-2}$ in a large $\left(35,000 \mathrm{~m}^{2}\right)$ sand patch (Horseshoe Patch) amid a bed of Syringodium filiforme off St. Croix, US Virgin Islands (Scheibling, 1980b). In 1977, $O$. reticulatus in Horseshoe Patch were extremely aggregated from June to October when large numbers of asteroids migrated throughout the patch in protracted grazing fronts. In this study, the dynamics of these aggregations are investigated by

\footnotetext{
- Present address: Biology Department, University of South
} Florida, Tampa, Florida 33620, USA. monitoring the density, dispersion and movements of individuals. In addition, the effects of intensive grazing by $O$. reticulatus on the substratum are assessed by measurements of the rate of disturbance and the reduction in chlorophyll concentration of the sediment. The ecological significance of the phenomenon to the asteroid population and sand patch community is discussed.

\section{MATERIALS AND METHODS}

The migration of a front of Oreaster reticulatus (L.) within the southern half of Horseshoe Patch (Fig. 1) was monitored over a 10-wk period (June 19-Aug. 30) by visually mapping the location of the front and the distribution of asteroid density during surveys with SCUBA. A reference framework of fixed station markers throughout the patch was used (Scheibling, 1980b).

A section of the front was monitored at 24 -h intervals for $1 \mathrm{wk}$ (Aug. 1-7). A study grid $(20 \times 40 \mathrm{~m})$ (Fig. 1), encompassing the front and the area in its advance, was delineated by graduated (meters) nylon lines: two fixed longitudinal lines (40 m), parallel to each other at a $10-\mathrm{m}$ interval, and a moveable lateral line (5 m) extended perpendicularly to either side of the fixed 

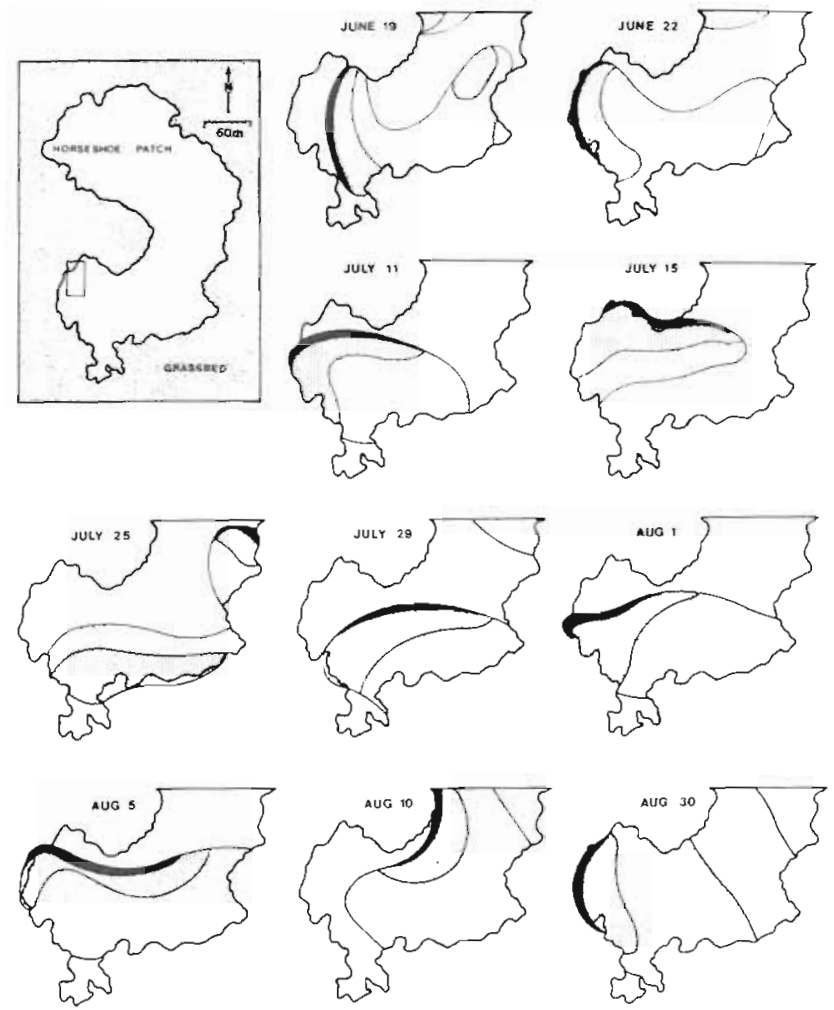

Fig. 1. Map of Horseshoe Patch indicating the location of the study grid, and sequential maps of the distribution of the density of Oreaster reticulatus within the south arm of the patch over time; dark bands (fronts): $2-7$ individuals $\mathrm{m}^{-2}$; dense stippling: $0.5-2$ individuals $\mathrm{m}^{-2}$; sparse stippling: 0.01-0.5 individuals $\mathrm{m}^{-2}$; blank areas: 0-0.01 individuals $\mathrm{m}^{-2}$

lines. The lines were suspended above the bottom to avoid interference to asteroid movement. The density of Oreaster reticulatus in 5 -m-square $\left(25 \mathrm{~m}^{2}\right)$ blocks (grid units) was measured on successive days. The leading edge of the front was located by rectangular coordinates at 5 -m intervals across the grid; straight lines connecting these points delineated its position. Where a leading edge line intersected a 5-m-square block, the density of $O$. reticulatus was recorded in terms of the area delimited by that line.

The rate of advance of the front was calculated as the displacement of the leading edge over $24 \mathrm{~h}$, measured at the midpoints of the $5-\mathrm{m}$ intervals (perpendicular to the leading edge) and averaged across the grid. The rate of advance was measured only for sections of the front traversing the sand patch over 24 h (i.e., sections which had not encountered the bed of Syringodium filiforme). Movements of marked individuals (Scheibling, 1980b) over $24 \mathrm{~h}$ were measured by recording their positions as rectangular coordinates on successive days.

The dispersion of Oreaster reticulatus and of its feeding sites, indicated by sediment mounds, was measured by the variance: mean ratio $\left(s^{2} / \bar{x}\right)$ based on counts in $0.25 \mathrm{~m}^{2}$ quadrats. The significance of departures from randomness $\left(s^{2} / \bar{x}=1\right)$ was tested by the expression $\left(s^{2} / \overline{\mathrm{x}}\right)(N-1)$, which is referred to a $\chi^{2}$ distribution with $\mathrm{df}=N-1$ where $N=$ the number of quadrats sampled (Grieg-Smith, 1964).

The feeding rate of Oreaster reticulatus was measured over 24 - $h$ periods by counting feeding mounds in $0.25 \mathrm{~m}^{2}$ quadrats centrally positioned in each 5-msquare block of the grid. Feeding mounds were not obliterated by erosion or asteroid movements during a 24 -h period. The estimation of feeding rate on undisturbed substratum is based upon a simplified model, whereby all individuals occur in a distinct band/front which moves in a unidirectional manner. The area covered by the hypothetical front per day equals the length of the front times its displacement, and the number of feeding sites in that area divided by the number of asteroids in the front yields the feeding rate. In the natural situation, the area of the grid covered by the front per day was defined by the positions of the leading edge on successive days. To estimate feeding rate, the number of feeding sites within this area was extrapolated from counts in $0.25 \mathrm{~m}^{2}$ quadrats and divided by the number of asteroids present. The natural situation deviated from the model in that not all asteroids were contained in a distinct band. Scattered individuals occurred throughout the area; some had undoubtedly entered within $24 \mathrm{~h}$. However, their inclusion in the calculation of feeding rate is offset by their contribution to the number of feeding sites. Moreover, this method of estimation was confined to the first $4 \mathrm{~d}$ of observation when the configuration and movement of the front approximated the assumptions of the model.

The feeding rate of Oreaster reticulatus on disturbed substratum (the area of the grid covered by the front more than $24 \mathrm{~h}$ previously) was calculated similarly. The number of asteroids within this area during $24 \mathrm{~h}$ was estimated by averaging counts on successive days. Previous feeding mounds within the $0.25 \mathrm{~m}^{2}$ quadrats in this area had been carefully smoothed over, permitting enumeration of new mounds produced during $24 \mathrm{~h}$.

Sediment chlorophyll concentration was measured as an index of the abundance of photosynthetic microorganisms (e.g., diatoms, dinoflagellates, bluegreen algae) which are primary components of the microphagous diet of Oreaster reticulatus in Horseshoe Patch (Scheibling, 1979). Samples of surface sediments (top $5 \mathrm{~mm}$ ) were concurrently collected from (1) undisturbed substratum 1-2 $\mathrm{m}$ in advance of the front, (2) freshly disturbed substratum between feeding mounds along the trailing edge of the front, and (3) recently disturbed substratum $15-20 \mathrm{~m}$ behind the front. Five 
samples of ca $5 \mathrm{~g}$ dry weight of sediment were taken at each location with a plastic corer (3-cm diam.) and analyzed for total chlorophyll concentration (Strickland and Parsons, 1968).

\section{RESULTS}

A dense aggregation of Oreaster reticulatus in the southern half of Horseshoe Patch migrated continuously over a 10-wk period (Fig. 1). The surrounding grassbed (Syringodium filiforme) imposed a barrier to the asteroids, and deflected and refracted the advance of the front (Fig. 2). A split in the aggregation occurred (July 25) with the two subgroups then moving separately. Successive invasions of local areas by the front occurred at 3 - to 4-wk intervals.

The front advanced through the study grid during Aug. 1-4 (Fig. 3). Density was maximal within $0.5 \mathrm{~m}$ of the leading edge, averaging $13.2(\mathrm{SE}= \pm 1.1)$ individuals $\mathrm{m}^{-2}$ (based on a sample of 18 contiguous 0.25 $\mathrm{m}^{2}$ quadrats), and decreased markedly in the wake of the 3-5 m-wide front to less than 0.7 individuals $\mathrm{m}^{-2}$. The dispersion of Oreaster reticulatus along the leading edge was significantly uniform $\left(s^{2} / \bar{x}=0.428\right.$; $\left.N=18 ; \chi^{2}, P<0.05\right)$, approximating the configuration of 'closest packing' (contiguity) of radially symmetrical organisms.

The rate of advance of the front averaged $7.3 \mathrm{~m} \mathrm{~d}^{-1}$ (range $=6.9-7.8 \mathrm{~m} \mathrm{~d}^{-1}$ ) and was positively correlated with the density of Oreaster reticulatus (Spearman's rank correlation test, $P<0.01$ ) (Fig. 4). Before contact with the grassbed (Aug. 2-4), 78.3\% of movements of individual $O$. reticulatus $(N=23)$ originating either within the front or behind it terminated within the front at its subsequent position after $24 \mathrm{~h}$ (Fig. 5). After contact (Aug. 4-7), a reversal in the orientation of movement occurred within the aggregation. Only $30.8 \%$ of all recorded movements $(N=26)$ terminated within the front; most of these (5 out of 8 ) were recorded during August 6-7, marking the advance of small cluster of asteroids around the grassbed (Fig. 5).

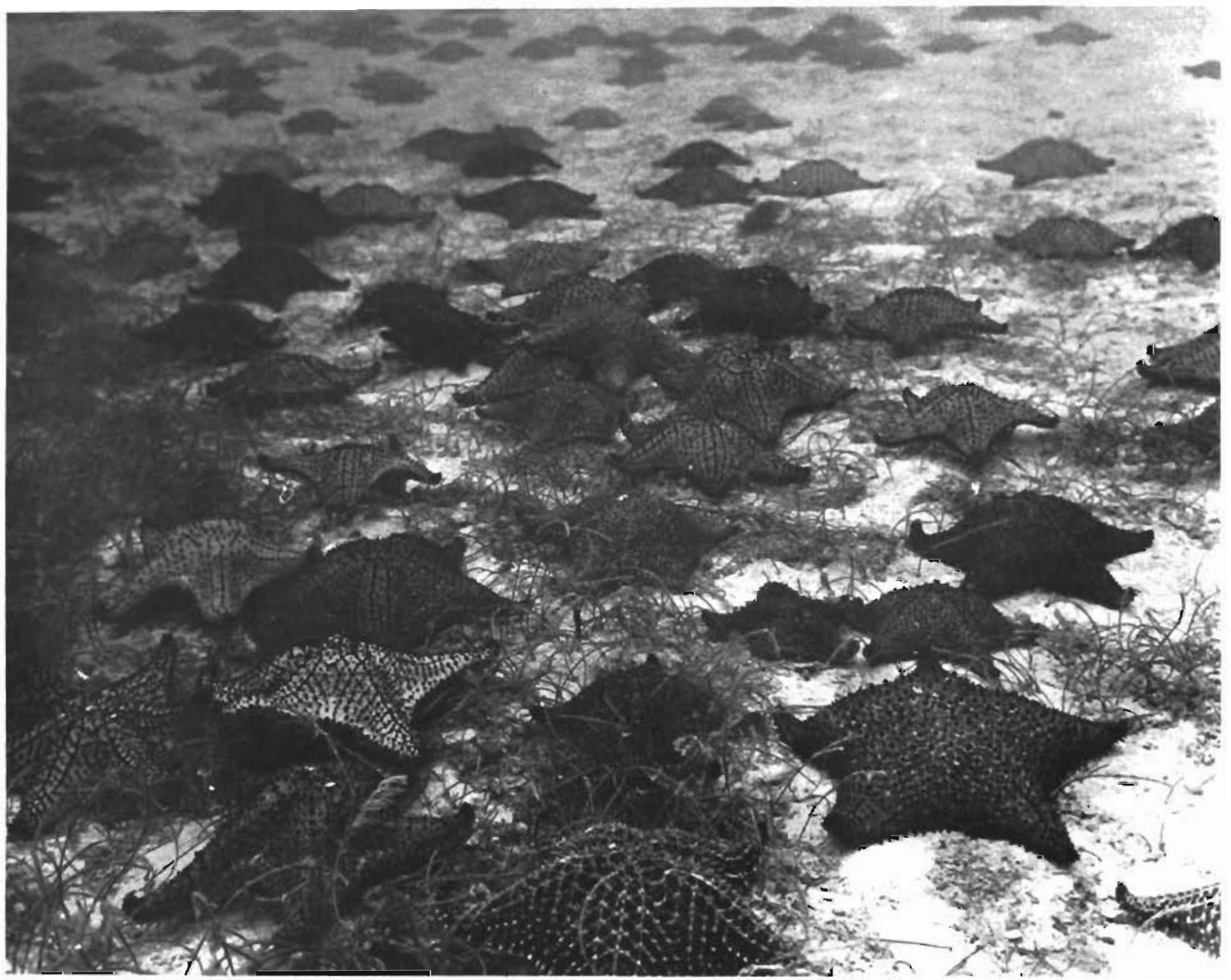

Fig. 2. Oreaster reticulatus. Front encountering the grassbed (Syringodium filiforme) bordering Horseshoe Patch 

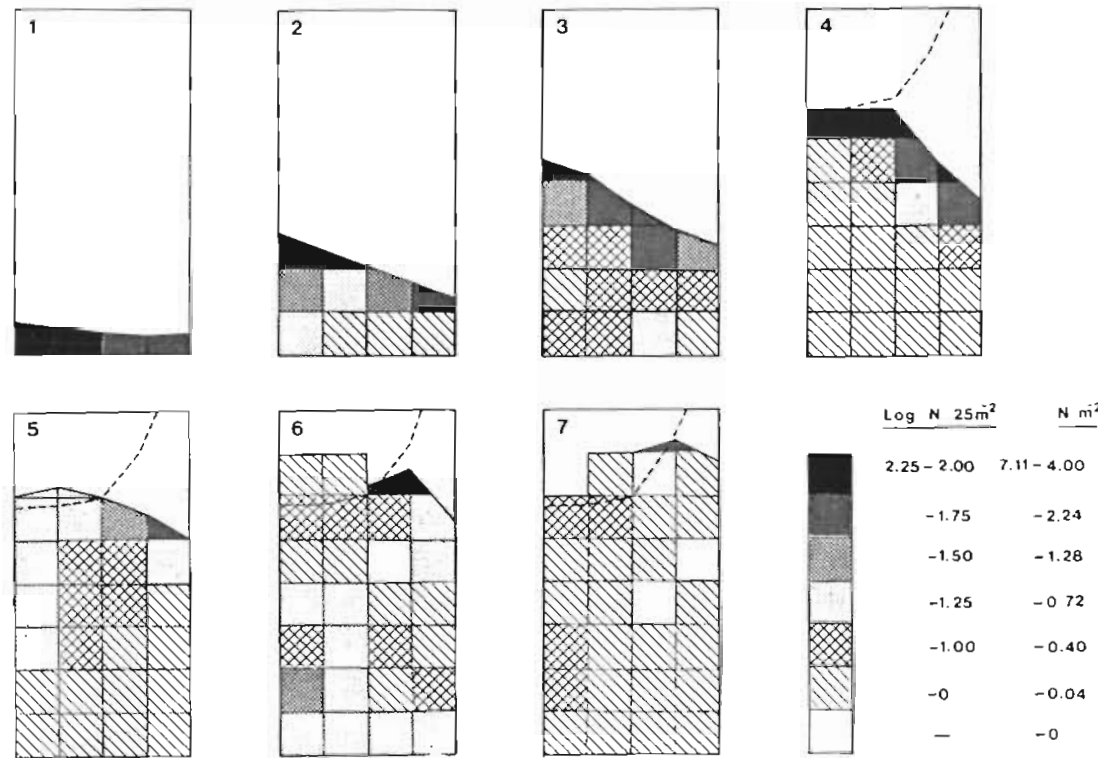

Fig. 3. Oreaster reticulatus. Distribution of the density within 5-m-square blocks in the study grid over time. Numbers represent consecutive days; dashed line delimits grassbed/sand patch border. Density classes designated according to log transformation of number of individuals $25 \mathrm{~m}^{-2}$ block $\left(\log \mathrm{N} 25 \mathrm{~m}^{-2}\right)$ due to exponential decrease in density with distance from leading edge of front. Corresponding untransformed class limits given as individuals $\mathrm{m}^{-2}\left(\mathrm{~N} \mathrm{~m}^{-2}\right)$

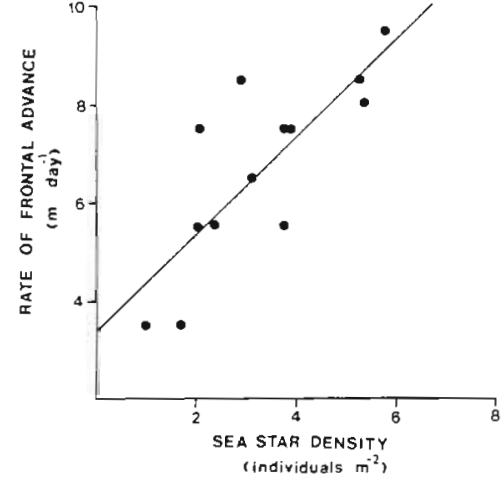

Fig. 4. Oreaster reticulatus. Relationship between daily rate of advance of the front measured at $5-\mathrm{m}$ intervals across the grid, and the asteroid density within the respective 5-msquare blocks encompassing the front
The Rayleigh test indicated that the orientation of movement was significantly nonrandom both before $(P$ $<0.001)$ and after $(P<0.05)$ contact with the grassbed. The distance covered by $O$. reticulatus at the front upon undisturbed substratum during 24 h $(\bar{x} \pm \mathrm{SE}=8.5 \pm 0.4 \mathrm{~m} ; N=17)$ was significantly less than the distance covered by those behind the front on recently disturbed substratum during part or all of a 24-h interval (14.4 $\pm 1.4 \mathrm{~m} ; N=32)$ (Mann Whitney U test, $P<0.01$ ). The greatest distances were recorded for individuals originating behind the front and moving into it during $24 \mathrm{~h}(18.4 \pm 2.4 ; N=9)$.

The mean feeding rate of Oreaster reticulatus (feeding sites asteroid ${ }^{-1} \mathrm{~d}^{-1}$ ) did not differ significantly between undisturbed and disturbed substratum (Table 1)
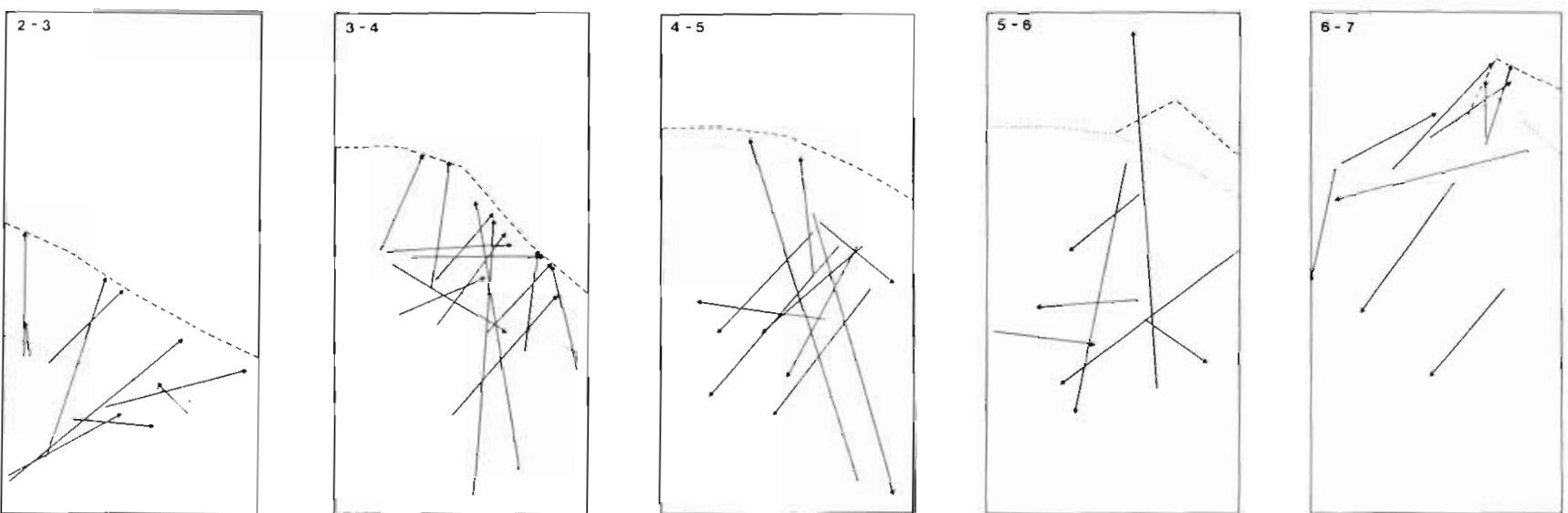

Fig. 5. Oreaster reticulatus. Displacement vectors of individuals within the study grid over 24 h. Numbers: two successive days; dotted and dashed lines: position of front of the first and second day, respectively 
Table 1. Oreaster reticulatus. Feeding rate on (a) undisturbed substratum and (b) disturbed substratum, expressed as number of feeding sites asteroid ${ }^{-1} \mathrm{~d}^{-1}$

\begin{tabular}{|c|c|c|c|}
\hline $\begin{array}{l}\text { Period } \\
(24 \mathrm{~h})\end{array}$ & $\begin{array}{c}\text { Asteroid } \\
\text { density } \\
\text { (asteroids } \\
\mathrm{m}^{-2} \text { ) }\end{array}$ & $\begin{array}{l}\text { Feeding } \\
\text { site density } \\
\text { (feeding } \\
\text { sites } \mathrm{m}^{-2} \text { ) }\end{array}$ & $\begin{array}{l}\text { Feeding rate } \\
\text { (sites } \\
\text { asteroid }^{-1} \\
\mathrm{~d}^{-1} \text { ) }\end{array}$ \\
\hline (a) Aug. 1-2 & 2.01 & 34.0 & 16.9 \\
\hline $2-3$ & 2.60 & 36.7 & 14.1 \\
\hline $3-4$ & 2.92 & 37.2 & 12.7 \\
\hline $\begin{array}{r}\text { mean } \\
( \pm S E)\end{array}$ & $\begin{array}{c}2.51 \\
( \pm 0.26)\end{array}$ & $\begin{array}{r}36.0 \\
( \pm 1.0)\end{array}$ & $\begin{array}{r}14.6 \\
( \pm 1.2)\end{array}$ \\
\hline (b) Aug. 2-3 & 0.49 & 6.0 & 12.2 \\
\hline $3-4$ & 0.41 & 6.4 & 16.0 \\
\hline $4-5$ & 0.33 & 5.1 & 15.5 \\
\hline $5-6$ & 0.53 & 4.8 & 9.1 \\
\hline $6-7$ & 0.46 & 5.4 & 11.7 \\
\hline mean & 0.44 & 5.5 & 12.9 \\
\hline$( \pm S E)$ & $( \pm 0.04)$ & $( \pm 0.3)$ & $( \pm 1.3)$ \\
\hline
\end{tabular}

(Mann Whitney $\mathrm{U}$ test, $P>0.20$ ). The number of feeding sites formed during a 48 -h interval was compared between samples of smoothed and unaltered (control) areas to test for an artifact of smoothing. For the sample of smoothed area, the number of feeding sites formed in each $0.25 \mathrm{~m}^{2}$ quadrat in an area covered by the front during $24 \mathrm{~h}$ was added to the number formed in the respective quadrats (after smoothing) during the next $24 \mathrm{~h}$. For the control sample, feeding sites were enumerated in an area adjacent to the grid which had been covered by the front $48 \mathrm{~h}$ before. The mean of the sample of smoothed area (10.5 \pm 0.6 feeding sites $0.25 \mathrm{~m}^{-2} ; N=20$ ) did not differ significantly from that of the control sample $(11.3 \pm 0.3$ feeding sites $0.25 \mathrm{~m}^{-2} ; N=15$ ), indicating that smoothing did not affect subsequent feeding activity.

The dispersion of feeding sites in areas covered by the front during $24 \mathrm{~h}$ (Aug. 1-4) approximated a uniform distribution $\left(s^{2} \sqrt{x}=0.49 ; N=20 ; \chi^{2}, P<0.10\right)$ consistent with that of Oreaster reticulatus in the front. The uniformity of feeding sites increased with density: $s^{2} \sqrt{x}=0.15\left(N=15 ; \chi^{2}, P<0.001\right)$ in an area covered by the front $48 \mathrm{~h}$ previously (control sample: see above), indicating that asteroids in the wake of the front fed at the interstices of previous feeding sites.

The rate of sediment turnover by the feeding activity of Oreaster reticulatus was estimated as the average number of feeding sites formed $\mathrm{m}^{-2} \mathrm{~d}^{-1}$ (Table 1) multiplied by the average area of a feeding site. Surface sediment within this circular area defined by the radius of the feeding asteroid was raked by the tube feet to form the central mound upon which the cardiac stomach was everted (Scheibling, 1979). The average area of a feeding site based on the average radius of $O$. reticulatus in the Horseshoe Patch $(\bar{R}=12.8 \mathrm{~cm}$; Scheibling, 1980b) was $515 \mathrm{~cm}^{2}$. Recently undisturbed substratum swept by the front was turned over ca. 1.9 times within $24 \mathrm{~h}$. The turnover rate due to trailing individuals was ca. 0.3 times $d^{-1}$, or about once every $3.3 \mathrm{~d}$. Therefore, the surface sediment was turned over almost 4 times over a $1-w k$ period following the passage of the front.

The degree of feeding site overlap in the area swept by a front during $24 \mathrm{~h}$ was estimated from the density of feeding sites in $0.25 \mathrm{~m}^{2}$ quadrats. The average density ( 9 feeding sites $0.25 \mathrm{~m}^{-2}$, Table 1) was 2.25 times greater than that expected without overlap (4 feeding sites $0.25 \mathrm{~m}^{-2}$ ) and represented an areal overlap of $73 \%$ per feeding site (Fig. 6) assuming a uniform distribution of average-sized feeding sites. The high degree of primary overlap indicated by the model was probably accompanied by lesser degrees of secondary and tertiary overlap under natural conditions.

The mean chlorophyll concentration of undisturbed substratum in advance of the front was significantly higher than that of the inter-mound raked areas along the trailing edge (Mann Whitney $U$ test, $P<0.01$ ) (Table 2). This indicates that microphytes predominantly occurred in a thin surface layer of sediment which was raked into the feeding mound. A velutinous, greenish-brown film was conspicuous on the undisturbed substratum; its removal by Oreaster reticulatus resulted in a marked discontinuity in the color and texture of the substratum at the front. Between 15 and $20 \mathrm{~m}$ to the rear of the front, the numerous feeding mounds formed by the front $3-4 \mathrm{~d}$ previ-

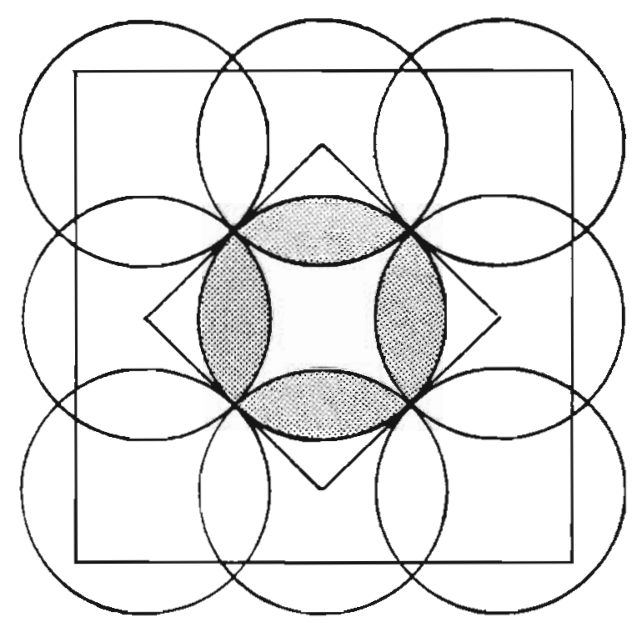

Fig. 6. Oreaster reticulatus. Hypothetical uniform distribution of average-sized (radius $=12.8 \mathrm{~cm}$ ) feeding sites (circles) at a density of 9 sites $0.25 \mathrm{~m}^{-2}$ (large, outer square). Difference between area of small, inner square $\left(655 \mathrm{~cm}^{2}\right)$ and that of inscribed circle $\left(515 \mathrm{~cm}^{2}\right)$ equals the area of non-overlap (140 $\mathrm{cm}^{2}$ ) within the feeding site. Therefore, the area of overlap per average feeding site is $375 \mathrm{~cm}^{2}$ (shaded) 
Table 2. Spatial variations in chlorophyll concentration of surface sediments associated with disturbance by Oreaster reticulatus

\begin{tabular}{|lc|}
\hline Location & $\begin{array}{c}\text { Mean } \pm \text { SE chloro- } \\
\text { phyll concentration } \\
\left(\mu \mathrm{g} \text { pigment } \mathrm{g}^{-1}\right. \\
\text { dry wt. sediment })\end{array}$ \\
\hline In advance of front $(1-2 \mathrm{~m})$ & $774 \pm 99$ \\
Trailing edge of front $($ raked areas $)$ & $282 \pm 18$ \\
To rear of front $(15-20 \mathrm{~m})$ & $336 \pm 62$ \\
\hline
\end{tabular}

ously were smoothed by currents and the substratum lacked a discernible microalgal-detrital film. The mean chlorophyll cocentration in this area was not significantly different from that of freshly raked areas (Mann Whitney $U$ test, $P<0.20$ ) and significantly lower than that of undisturbed substratum in advance of the front (Mann Whitney U test, $P<0.01$; Table 2).

\section{DISCUSSION}

The formation of dense fronts marked a period of maximal aggregation for the population of Oreaster reticulatus in Horseshoe Patch, concurrent with the peak of gonadal growth and spawning (Scheibling, $1980 \mathrm{~b})$. An intrinsic increase in gregariousness, possibly associated with reproductive state, may precipitate front formation as aggregations of $O$. reticulatus are localized. Particulate organic matter in the surface sediments is rapidly removed by intense feeding activity within aggregations, resulting in large-scale patchiness of the organic content of the substratum. As aggregations migrate across the patch, the movement of individuals along the leading border is slowed as they advance into nutrient-rich sediments. Trailing individuals, foraging upon disturbed sediments, move farther and spend less time at feeding sites, eventually overtaking those in the lead to form a high-density front. The dissolution of fronts may occur by a reverse mechanism: aggregations become more diffuse resulting in a decrease in the large-scale heterogeneity of the organic content of the substratum and a concomitant increase in the uniformity of rates of movement of foraging individuals. Dense fronts of $O$. reticulatus persisted for ca. 1 month following the completion of spawning in Horseshoe Patch (Sept., 1977). The lag may reflect the time required for the dissipation of fronts once gregariousness associated with reproduction has declined. Fronts of $O$. reticulatus may be an atypical phenomenon, contingent upon a dense population in a confined habitat. They were not observed among less dense populations in expansive sand or grassbed habitats (Scheibling, 1980a, b)

Movement of Oreaster reticulatus was relatively unidirectional within fronts; individuals constantly circumvented and/or partially straddled one another to locate suitable feeding sites. Thus, the rate of advance varied directly with asteroid density along the extent of a front, resulting in curvature of the leading edge. Penetration of the dense bed of Syringodium filiforme by fronts rarely exceeded the first few meters; the asteroids generally moved along the border or reversed direction. The grassblades severely impeded the mobility of $O$. reticulatus, thereby limiting its foraging ability (Scheibling, 1980a, b). A spontaneous change in the direction of migration occurred occasionally along a front, apparently in response to shifts in asteroid density, suggesting a strong intraspecific attraction.

The similarity in the feeding rate of Oreaster reticulatus (feeding sites asteroid ${ }^{-1} \mathrm{day}^{-1}$ ) on undisturbed and disturbed substratum is attributed to the offsetting differences in the time spent moving between feeding sites and the time spent at them, which in turn are related to differences in the nutritional content of the substratum as described above. However, the time spent feeding would be greater on undisturbed substratum.

The marked reduction in chlorophyll concentration within the raked area of a feeding site and the high degree of feeding site overlap in the area covered by a front suggest intense intraspecific competition for food. The degree of overlap between successive feeding sites most frequently realized by independently foraging Oreaster reticulatus was an order of magnitude lower (Scheibling, 1979). The population of Horseshoe Patch was clearly food-limited as evidenced by the small size and minimal nutrient storage capacity and reproductive effort of individuals relative to other less dense, less aggregated populations (Scheibling, 1979, 1980b).

Predatory asteroids have been identified as important determinants of community structure among macrobenthos assemblages in diverse marine habitats: the temperate rocky intertidal (Paine, 1966, 1974; Dayton, 1971), the antarctic sublittoral (Dayton et al., 1974) and tropical coral reefs (Porter, 1972, 1974; Laxton, 1974; Glynn, 1976). Similarly, microphagous feeding by Oreaster reticulatus may control patterns of species diversity, abundance and distribution among microand meiobenthos communities within the surface sediments. The intense disturbance imposed by asteroid fronts may maintain these communities in a low successional state by favoring species which are resilient to periodic decimation and/or opportunistic species capable of rapid colonization of 'clean' sediment provided in the wake of fronts (e. g., blue-green algae). 
The dynamic, heterogeneous distribution of particulate organic matter generated by the feeding activity of migratory fronts of Oreaster reticulatus may also affect the distribution and abundance of potential macrofaunal competitors which forage at the sediment surface (e. g., urchins, crabs, fish). The thorough turnover of surface sediments at approximately 3 - to 4 -wk intervals, probably precludes recruitment of macrofaunal larvae within Horseshoe Patch. The larvae of $O$. reticulatus itself may settle and undergo early post-metamorphic development in the surrounding grassbeds (Scheibling, 1980b).

Acknowledgements. This paper is based on research conducted in partial fulfillment of the doctoral requirements of the Marine Sciences Centre, McGill University, Canada. I am grateful to Dr. J. M. Lawrence, Dr. C. M. Lalli and Dr. H. M. Reiswig for critically reviewing the manuscript and to Dr. R. F. Dill for the use of research facilities at the West Indies Laboratory in St. Croix. I am indebted to my wife Anna for her impeccable assistance in the field. Funding was provided by the National Research Council of Canada.

\section{LITERATURE CITED}

Breen, P. A., Mann, K. H. (1976). Destructive grazing of kelp by sea urchins in Eastem Canada. J. Fish. Res. Bd Can. 33: $1278-1283$

Dayton, P. K. (1971). Competition, disturbance and community organization: The provision and subsequent utilization of space in a rocky intertidal community. Ecol. Monogr. 41: 351-389

Dayton, P. K., Robilliard, G. A., Paine, R. T., Dayton, L. B. (1974). Biological accommodation in the benthic community at McMurdo Sound, Antarctica. Ecol. Monogr. 44: $105-128$

Endean, R. (1973). Population explosions of Acanthaster planci and associated destruction of hermatypic corals in the Indo-West Pacific region. In: Jones, O. A., Endean, R. (eds) Biology and geology of coral reefs, Vol. II, Biology I. Academic Press, New York, pp. 389-438
Glynn, P. W. (1976). Some physical and biological determinants of coral community structure in the eastern Pacific. Ecol. Monogr. 46: 431-456

Greig-Smith, P. (1964). Quantitative plant ecology, Buttersworths, London

Laxton, J. H. (1974). Aspects of the ecology of the coral-eating starfish Acanthaster planci. Biol. J. Linn. Soc. 6: 19-45

Leighton, D. L., Jones, L. G., North, W. J. (1966). Ecological relationships between giant kelp and sea urchins in southern California. In: Young, E. G., McLachlan, J. L. (eds) Proceedings of 5th international seaweed symposium. Pergamon Press, Oxford, pp. 141-153

Mattison, J. E., Trent, J. D., Shanks, A. L., Akin, T. B., Pearse, J. S. (1977). Movement and feeding activity of red sea urchins (Strongylocentrotus franciscanus) adjacent to a kelp forest. Mar. Biol. 39: 25-30

Paine, R. T. (1966). Food web complexity and species diversity. Am. Nat. 100: 65-75

Paine, R. T. (1974). Intertidal community structure: Experimental studies on the relationship between a dominant competitor and its principal predator. Oecologia 15: 93-120

Porter, J. W. (1972). Predation by Acanthaster and its effect on coral species diversity. Am. Nat. 106: 487-492

Porter, J. W. (1974). Community structure of coral reefs on opposite sides of the Isthmus of Panama. Science, N. Y. 186: $543-545$

Reese, E. (1966). The complex behavior of echinoderms. In: Boolootian, R. A. (ed.) Physiology of Echinodermata. Wiley Interscience, New York, pp. 157-218

Scheibling, R. E. (1979). The ecology of Oreaster reticulatus (L.) (Echinodermata: Asteroidea) in the Caribbean. Ph. D. thesis, McGill University, Montreal

Scheibling, R. E. (1980a). Abundance, spatial distribution and size structure of populations of Oreaster reticulatus (L.) (Echinodermata: Asteroidea) in seagrass beds. Mar. Biol. (in press)

Scheibling, R. E. (1980b). Abundance, spatial distribution and size structure of populations of Oreaster reticulatus (L.) (Echinodermata: Asteroidea) on sand bottoms. Mar. Biol. (in press)

Strickland, J. D. H., Parsons, T. R. (1968). A practical handbook of seawater analysis, Fisheries Research Board of Canada, Ottawa

This paper was presented by Dr. J. Lawrence; it was accepted for printing on February 28, 1980. 